\title{
BMJ Open Moving from prefabricated temporary housing to public reconstruction housing and social isolation after the Great East Japan Earthquake: a longitudinal study using propensity score matching
}

Takuya Sekiguchi, ${ }^{1,2}$ Yoshihiro Hagiwara, ${ }^{2}$ Yumi Sugawara, ${ }^{3}$ Yasutake Tomata, ${ }^{\circ} 4$ Fumiya Tanji, ${ }^{3}$ Yutaka Yabe, ${ }^{2}$ Eiji Itoi, ${ }^{2}$ Ichiro Tsuji ${ }^{3}$

To cite: Sekiguchi T, Hagiwara Y, Sugawara Y, et al. Moving from prefabricated temporary housing to public reconstruction housing and social isolation after the Great East Japan Earthquake: a longitudinal study using propensity score matching. BMJ Open 2019;9:e026354. doi:10.1136/ bmjopen-2018-026354

- Prepublication history and additional material for this paper are available online. To view these files, please visit the journal online (http://dx.doi. org/10.1136/bmjopen-2018026354).

Received 28 August 2018 Revised 11 January 2019 Accepted 16 January 2019

Check for updates

(c) Author(s) (or their employer(s)) 2019. Re-use permitted under CC BY-NC. No commercial re-use. See rights and permissions. Published by BMJ.

For numbered affiliations see end of article.

Correspondence to Dr Yoshihiro Hagiwara; hagi@med.tohoku.ac.jp

\section{ABSTRACT}

Objectives After the Great East Japan Earthquake (GEJE) of 2011, many survivors have been forced to live in prefabricated temporary housing, which is uncomfortable and insufficiently durable for permanent living. Public reconstruction housing has been built to improve their living conditions; however, those moving have to rebuild personal relationships and adapt to a new environment. This study examined whether survivors moving to public reconstruction housing became more socially isolated than those remaining in prefabricated temporary housing.

Design, setting and participants Self-report questionnaire data collected in 2015 (4 years after the GEJE) were used as the baseline for follow-up surveys in 2016 and 2017, as many survivors moved from prefabricated temporary housing to public reconstruction housing from 2015. We analysed longitudinal data from 393 survivors, distinguishing those who moved to public reconstruction housing during the 5th year after the disaster from those who remained in prefabricated temporary housing. Participants were assessed using the Lubben Social Network Scale-6 (LSNS-6) in all three surveys, with social isolation defined by a score of $<12 / 30$. To reduce the effect of selection bias, propensity score analysis was performed (178 of 393 participants were retained). We used a generalised estimated equation to evaluate the association between moving from prefabricated temporary housing to public reconstruction housing and changes in social isolation over 2 years.

Results LSNS-6 scores of the reconstruction housing group were worse than those of the prefabricated housing group between 4 and 6 years after the GEJE ( $P=0.006)$. Over the same period, social isolation worsened in the reconstruction housing group but improved in the prefabricated housing group ( $\mathrm{P}=0.002)$.

Conclusions Social isolation should be monitored while supporting survivors who moved to public reconstruction housing, and further longitudinal research is needed to clarify the risk of social isolation.
Strengths and limitations of this study

- This is the first study to examine the association between moving to public reconstruction housing and social isolation after a natural disaster.

- This study used a longitudinal design, requiring protracted efforts from the researchers and survivors to undertake surveys in the aftermath of a disaster.

- To minimise the differences between the two groups' characteristics, participants were matched using propensity scores

- Among the 937 participants who lived in prefabricated temporary housing, the analysed population of $393(41.9 \%)$ was relatively small.

- The participants had all lived in prefabricated temporary housing for at least 4 year, consequently, the results might suffer from overestimation.

\section{INTRODUCTION}

Social isolation is associated with a higher risk of various physical and psychological problems, including stroke, ${ }^{1}$ coronary heart disease, ${ }^{2} 3$ depression, ${ }^{4-6}$ mortality $^{7} 8$ and suicide. ${ }^{9}$ Survivors of natural disasters are at higher risk of social isolation due to the death of family or friends, and evacuation from their home community. Several recent studies have focused on the importance of social networks in the recovery process after natural disasters. ${ }^{1011}$

The Great East Japan Earthquake (GEJE), which was followed by a devastating tsunami, struck the northeastern coastal area of Japan on March 11, 2011, leaving approximately 18500 people dead or missing. ${ }^{12}$ Because the GEJE and tsunami destroyed over 390000 houses, Japanese municipal governments began to build prefabricated temporary 
housing during the acute phase after the calamity. ${ }^{13}$ Approximately 120000 survivors were forced to live in this housing. ${ }^{14}$ As the coastal areas are at a higher risk of future tsunamis, local governments have prevented the rebuilding of towns where survivors previously lived, insisting instead that new towns be developed for them on mountainsides or at a higher elevation along the coast. ${ }^{13}$ Due to the length of time required to accomplish these recovery plans, ${ }^{15}$ many survivors have been forced to live in prefabricated temporary housing for several years after the GEJE. ${ }^{14}$

Public reconstruction housing plays an important role in providing permanent houses for the survivors of natural disasters, as demonstrated after the HanshinAwaji Earthquake in $1995 .{ }^{16}$ From around 4 years after the disaster, many survivors who were initially accommodated in prefabricated temporary housing started to move to public reconstruction housing. ${ }^{17}$ Their new surroundings require them to rebuild personal relationships and to adapt to a different environment. An increase in suicide and dying alone (kodoku-shi, in Japanese) was highlighted among residents of public reconstruction housing during the recovery phase following the Hanshin Awaji Earthquake. ${ }^{18}$ Therefore, it is crucial to monitor such psychosocial issues following the GEJE. However, no study has yet focused on the social isolation of GEJE survivors relocated to public reconstruction housing. This study aims to examine whether survivors who moved to public reconstruction housing became more socially isolated compared with those who remained in prefabricated temporary housing after the GEJE.

\section{METHODS}

\section{Study design and participants}

Study participants comprised GEJE survivors (aged 18 or over) who lived in the severely damaged coastal areas of Ogatsu and Oshika in Ishinomaki city, and Wakabayashi ward in Sendai city, all situated in Miyagi Prefecture. ${ }^{19}$ The design of this panel study was reported in detail elsewhere. ${ }^{20}$ Health surveys involving an interview questionnaire and health check-up were conducted from June to November 2011, and ongoing questionnaire surveys have been repeated every 6 months thereafter. A self-report questionnaire and form for obtaining informed consent were mailed to all participants in the surveys analysed in his study.

Data from the questionnaire survey completed from November 2014 to February 2015 (4years after the GEJE) were used as baseline data in this study, because many residents initially accommodated in prefabricated temporary housing have moved to public reconstruction housing. Approximately $30 \%$ of the survivors had been living in prefabricated temporary housing 4 years after the GEJE. The proportion has decreased gradually (21\% and $10.4 \%$ after 5 and 6 years after the GEJE); on the contrary, the proportion of the survivors who lived in public reconstruction housing has increased $(2.1 \%$,
$9.0 \%$, and $13.1 \%$ after 4,5 and 6 years after the GEJE). Among the 2762 individuals who responded to the questionnaire, 937 lived in prefabricated temporary housing at that time. We excluded one participant who did not respond to questions concerning social isolation. Among the 936 remaining participants, we excluded 117 who did not respond to the questionnaire survey conducted from November 2015 to January 2016 (1 year after baseline; 5 years after the GEJE). We then excluded a further 11 who did not respond to questions on their living environment, and 123 who did not live in either prefabricated housing or public reconstruction housing. Among the 688 participants who lived in prefabricated temporary housing (555) or public reconstruction housing (133), 72 did not respond to the questionnaire survey conducted from November 2016 to January 2017 (2 years after baseline; 6years after the GEJE), and so were excluded. We then excluded eight who did not respond to questions on their living environment, 115 who no longer lived in prefabricated temporary housing or public reconstruction housing, 99 who moved house between the questionnaire surveys conducted 5 and 6 years after the GEJE, and one who did not respond to the LSNS-6 questions. Thus, a total of 393 participants were included in the analysis (figure 1).

\section{Measurements}

Exposure: moving to public reconstruction housing

Local governments around the GEJE-affected areas recruited survivors whose houses were completely destroyed, and who were unable to rebuild their houses, to live in public reconstruction housing, allowing the survivors to decide for themselves. Participants' living environment at 4, 5 and 6 years after the GEJE was determined through a self-report questionnaire. We divided the participants into two groups: survivors who moved from prefabricated temporary housing to public reconstruction housing during the 5th year after the GEJE ('the reconstruction housing group') and those who continued to live in prefabricated temporary housing ('the prefabricated housing group').

\section{Outcome: social isolation}

The Lubben Social Network Scale (LSNS-6) has been widely used to assess social integration and to screen for social isolation. ${ }^{21}$ The reliability and validity of the Japanese version of LSNS-6 has previously been confirmed. ${ }^{22}$ The measure comprises a set of three questions that evaluate family ties and a comparable set of three questions that evaluate friendship ties: (1) 'How many relatives do you see or hear from at least once a month?'; (2) 'How many relatives do you feel close to such that you could call on them for help?'; (3) 'How many relatives do you feel at sufficient ease with to talk about private matters?'; (4) 'How many of your friends do you see or hear from at least once a month?' (5) 'How many friends do you feel close to such that you could call on them for help?' or (6) 'How many friends do you feel sufficiently at ease with to 


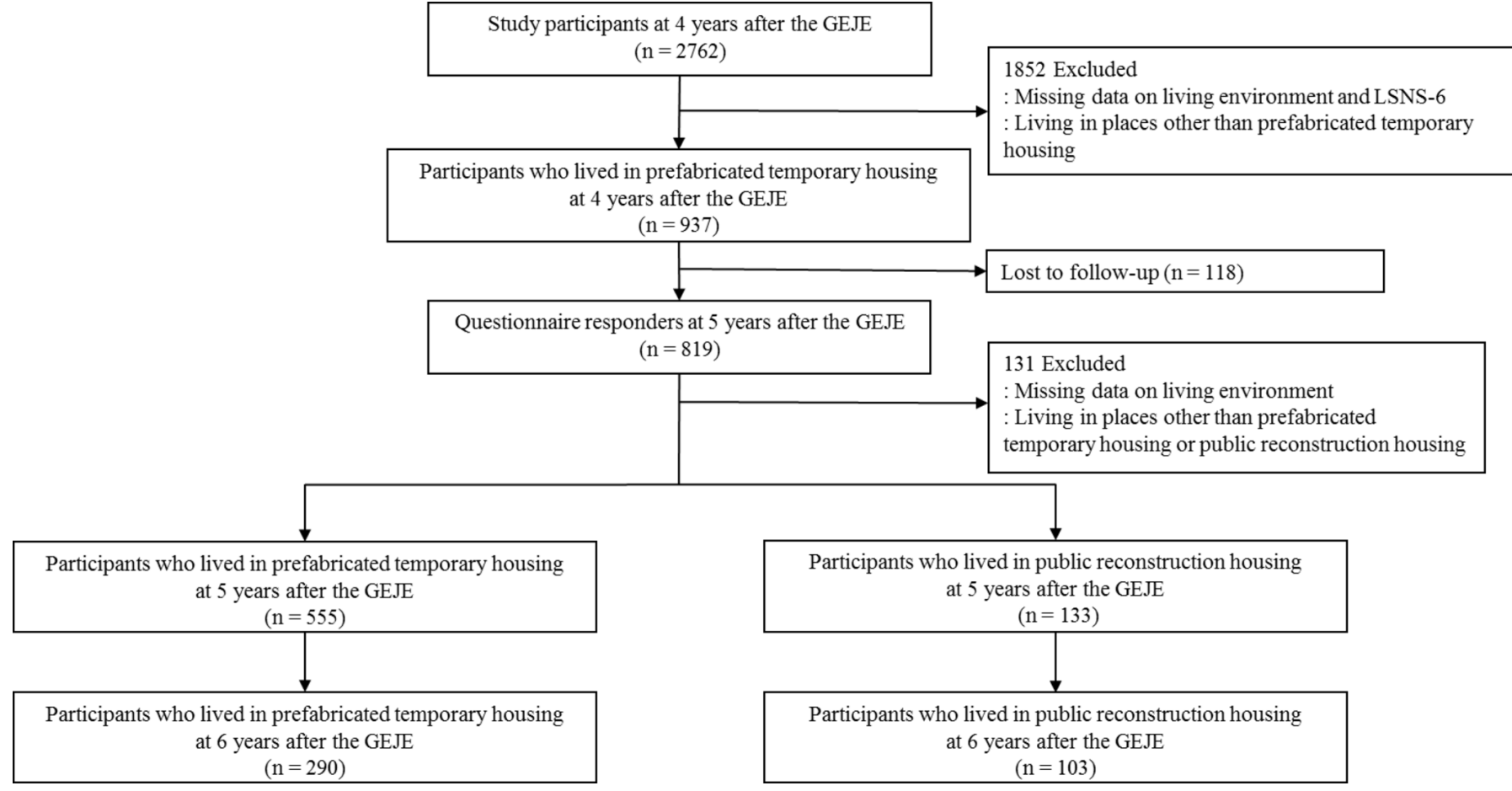

Figure 1 Flow diagram of the participants. GEJE, Great East Japan Earthquake; LSNS-6, Lubben Social Network Scale-6.

talk about private matters?' The possible responses and their scores are: 'none' ( 0 points), 'one' (one point), 'two' (two points), 'three or four' (three points), 'five to eight' (four points) and 'nine or more' (five points). The total score thus ranges from 0 to 30 . As suggested by Lubben $e t a l,{ }^{21}$ we classified individuals with scores of less than 12 as being socially isolated.

\section{Covariates}

The following variables at baseline (4 years after the GEJE) were included in the analysis as covariates: sex, age, body mass index (BMI; calculated using self-reported height and weight values), working status, drinking habits, smoking habits, physical activity (walking time per day), complications (hypertension, myocardial infarction, diabetes mellitus, or cerebral stroke), number of families living together, subjective economic hardship and psychological distress. Subjective economic hardship was assessed by the question: 'How do you feel about the current state of your household economy?' Available responses were 'fair', 'poor', 'poorer' and 'poorest'. ${ }^{14} 23$ Psychological distress was defined by a score of $\geq 10 / 24$ on the Kessler Psychological Distress Scale-6 (K6). ${ }^{24}$

\section{Statistical analysis}

To determine the impact of moving into public reconstruction housing and to reduce the effect of selection bias, propensity score analysis was performed using the following algorithm. ${ }^{25}$ Possible confounders were chosen for their potential association with the outcome based on clinical knowledge. Propensity scores were estimated using a logistic regression model with the following variables: sex (male or female), age ( $<65$ years old or $\geq 65$ years old), BMI $(<18.5,18.5$ to 25 , or $\geq 25)$, working status (unemployed or employed), drinking habits (non-drinker, $<45.6 \mathrm{~g}$ of alcohol/day, or $\geq 45.6 \mathrm{~g}$ of alcohol/day), smoking habits (non-smoker or smoker), walking time per day $(<30 \mathrm{~min} /$ day, $30 \mathrm{~min}$ to $<1$ hour/ day or $\geq 1$ hour/day), complications (hypertension, myocardial infarction, diabetes mellitus and/or cerebral stroke), number of families living together (1, 2, 3 to 4 or $\geq 5$ ), subjective economic hardship (fair, or poor to poorest), psychological distress (K6 score: $<10$ or $\geq 10$ ). For cases with missing values for a confounding variable, we created a separate missing category and included this in the model. The variables to be inserted into the multivariate models to calculate propensity scores were determined after screening for multicollinearity. According to their propensity scores, participants were matched in a 1-to-1 manner using the greedy nearest neighbour method. The area under the curve (AUC) and the Hosmer-Lemeshow test were calculated to respectively assess the model's performance and calibration.

Categorical variables were summarised as percentages. Continuous variables were summarised as means with SD. A $\chi^{2}$ test for categorical variables and Student t-test for continuous variables were conducted to compare baseline characteristics between the groups. A generalised estimated equation (GEE) was used to evaluate the association between moving from prefabricated temporary housing to public reconstruction housing and changes in social isolation. This model takes into account the relationship between repeated measurements for each individual. To gain a clearer picture of the association between moving to public reconstruction housing and 
any change in social isolation, we considered the LSNS-6 as (1) continuous (total scores of the LSNS-6), and (2) binary (socially isolated or not socially isolated) variables. Furthermore, the internal consistency of the LSNS-6 and K6 was assessed using Cronbach's alpha coefficient.

All statistical analyses were performed using SPSS V.24.0 (SPSS Japan Inc., Tokyo, Japan). A p value of $<0.05$ was considered statistically significant.

\section{Patient and public involvement}

The patients and public were not involved in the development of the research questions, outcome measures or study design. The patients were also not involved in the recruitment and performance of the study. We will disseminated the final results to the participants after the results are published in a peer-reviewed journal.

\section{RESULTS}

Propensity score matching and baseline

Of the 393 participants, 103 (26.2\%) were in the reconstruction housing group and $290(73.8 \%)$ were in the prefabricated housing group (figure 1). Participants' characteristics before propensity score matching are shown in table 1 . Before matching, the participants in

Table 1 Baseline characteristics according to changes in living environment before matching $(n=393)$

\begin{tabular}{|c|c|c|c|c|}
\hline \multirow[b]{3}{*}{ Living environment } & \multirow{3}{*}{$\begin{array}{l}\text { Baseline* }^{*} \\
\text { Follow-upt }\end{array}$} & \multicolumn{2}{|c|}{ Prefabricated temporary housing } & \multirow[b]{3}{*}{$P$ values } \\
\hline & & $\begin{array}{l}\text { Prefabricated } \\
\text { temporary housing }\end{array}$ & $\begin{array}{l}\text { Public reconstruction } \\
\text { housing }\end{array}$ & \\
\hline & & 290 & 103 & \\
\hline \multirow[t]{2}{*}{ Sex $(\%)$} & Male & 47.2 & 47.6 & 0.95 \\
\hline & Female & 52.8 & 52.4 & \\
\hline Age (continuous) & & $62.1(16.5)$ & $60.0(15.3)$ & 0.27 \\
\hline \multirow[t]{2}{*}{ Age (\%) } & $<65$ years old & 43.1 & 52.4 & 0.1 \\
\hline & $\geq 65$ years old & 56.9 & 47.6 & \\
\hline BMI (continuous) & & $24.3(3.8)$ & $23.7(3.8)$ & 0.86 \\
\hline \multirow[t]{3}{*}{ BMI (\%) } & $<18.5$ & 2.5 & 3 & 0.73 \\
\hline & $18.5-24.9$ & 57.7 & 61.6 & \\
\hline & $\geq 25$ & 39.8 & 35.4 & \\
\hline \multirow[t]{2}{*}{ Working status (\%) } & Unemployed & 53.7 & 53.9 & 0.97 \\
\hline & Employed & 46.3 & 46.1 & \\
\hline \multirow[t]{3}{*}{ Drinking habits (\%) } & Non-drinker & 65.9 & 66.7 & 0.13 \\
\hline & $<45.6 \mathrm{~g}$ of alcohol/day & 23.9 & 29.3 & \\
\hline & $\geq 45.6 \mathrm{~g}$ of alcohol/day & 10.2 & 4.0 & \\
\hline \multirow[t]{2}{*}{ Smoking habits (\%) } & Non-smoker & 77.8 & 77.1 & 0.88 \\
\hline & Smoker & 22.2 & 22.9 & \\
\hline \multirow[t]{3}{*}{ Walking time/day (\%) } & $<30 \min$ & 32.8 & 38.8 & 0.54 \\
\hline & 30 min-1 hour & 36.6 & 33.0 & \\
\hline & $\geq 1$ hour & 30.7 & 28.2 & \\
\hline Complications (\%) & presence & 15.5 & 22.3 & 0.12 \\
\hline \multirow{2}{*}{$\begin{array}{l}\text { Subjective economic status } \\
\text { (\%) }\end{array}$} & Fair & 25.8 & 26.2 & 0.93 \\
\hline & Poor to poorest & 74.2 & 73.8 & \\
\hline \multirow[t]{4}{*}{ Families live together (\%) } & 1 & 14.7 & 12.6 & 0.049 \\
\hline & 2 & 37.9 & 44.7 & \\
\hline & $3-4$ & 34.0 & 38.8 & \\
\hline & $\geq 5$ & 13.3 & 3.9 & \\
\hline \multirow[t]{2}{*}{ Psychological distress (\%) } & K6 scores: $<10$ & 83.9 & 78.4 & 0.22 \\
\hline & K6 scores: $\geq 10$ & 16.1 & 21.6 & \\
\hline
\end{tabular}

*Baseline: 4 years after the GEJE. The study participants had lived prefabricated temporary housing up to 4 years after the GEJE. †Follow-up: 5 and 6 years after the GEJE.

BMI, body mass index; GEJE, Great East Japan Earthquake. 
Table 2 Baseline characteristics according to changes in living environment after matching ( $n=178)$

\begin{tabular}{|c|c|c|c|c|}
\hline \multirow[b]{3}{*}{ Living environment } & \multirow{3}{*}{$\begin{array}{l}\text { Baseline* }^{\star} \\
\text { Follow-upt }\end{array}$} & \multicolumn{2}{|c|}{ Prefabricated temporary housing } & \multirow[b]{3}{*}{$P$ values } \\
\hline & & $\begin{array}{l}\text { Prefabricated } \\
\text { temporary housing }\end{array}$ & $\begin{array}{l}\text { Public reconstruction } \\
\text { housing }\end{array}$ & \\
\hline & & 89 & 89 & \\
\hline \multirow[t]{2}{*}{ Sex (\%) } & Male & 51.7 & 46.1 & 0.55 \\
\hline & Female & 48.3 & 53.9 & \\
\hline Age (continuous) & & $61.1(17.3)$ & $60.7(15.4)$ & 0.35 \\
\hline \multirow[t]{2}{*}{ Age (\%) } & $<65$ years old & 47.2 & 49.4 & 0.88 \\
\hline & $\geq 65$ years old & 52.8 & 50.6 & \\
\hline BMI (continuous) & & $24.3(4.2)$ & 23.7 (3.8) & 0.37 \\
\hline \multirow[t]{3}{*}{ BMI (\%) } & $<18.5$ & 1.2 & 2.4 & 0.95 \\
\hline & $18.5-24.9$ & 61.6 & 61.6 & \\
\hline & $\geq 25$ & 37.2 & 36.0 & \\
\hline \multirow[t]{2}{*}{ Working status (\%) } & Unemployed & 57.3 & 54.5 & 0.57 \\
\hline & Employed & 42.7 & 44.9 & \\
\hline \multirow[t]{3}{*}{ Drinking habits (\%) } & Non-drinker & 65.5 & 68.2 & 0.92 \\
\hline & $<45.6 \mathrm{~g}$ of alcohol/day & 31.0 & 27.1 & \\
\hline & $\geq 45.6 \mathrm{~g}$ of alcohol/day & 3.5 & 4.7 & \\
\hline \multirow[t]{2}{*}{ Smoking habits (\%) } & Non-smoker & 79.3 & 79.6 & 0.85 \\
\hline & Smoker & 20.7 & 20.4 & \\
\hline \multirow[t]{3}{*}{ Walking time/day (\%) } & $<30 \mathrm{~min}$ & 36.0 & 38.2 & 0.73 \\
\hline & 30 min-1 hour & 38.2 & 32.6 & \\
\hline & $\geq 1$ hour & 25.8 & 29.2 & \\
\hline Complications (\%) & presence & 24.7 & 21.3 & 0.72 \\
\hline \multirow[t]{2}{*}{ Subjective economic status (\%) } & Fair & 23.6 & 24.7 & 0.86 \\
\hline & Poor to poorest & 76.4 & 75.3 & \\
\hline \multirow[t]{4}{*}{ Families live together (\%) } & 1 & 12.4 & 14.6 & 0.89 \\
\hline & 2 & 48.3 & 43.8 & \\
\hline & $3-4$ & 33.7 & 37.1 & \\
\hline & $\geq 5$ & 5.6 & 4.5 & \\
\hline \multirow[t]{2}{*}{ Psychological distress (\%) } & K6 score: $<10$ & 77.0 & 81.8 & 0.62 \\
\hline & K6 score: $\geq 10$ & 23.0 & 18.2 & \\
\hline
\end{tabular}

*Baseline: 4 years after the GEJE. The study participants had lived prefabricated temporary housing up to 4 years after the GEJE. †Follow-up: 5 and 6 years after the GEJE.

BMI, body mass index; GEJE, Great East Japan Earthquake.

the reconstruction housing group were more likely to be living with five and more families than those in the prefabricated housing group. Participants in the reconstruction housing group tended to be younger than those in the prefabricated housing group, with no statistical significance. To minimise the differences between the two groups' baseline characteristics, participants were matched using propensity scores. The AUC was 0.70 , and the Hosmer-Lemeshow test was 0.23 . Finally, 178 out of 393 participants remained in the analysis. Among these participants, there were no significant differences in the baseline characteristics, nor any statistical differences in the covariates between the two groups (table 2).
Longitudinal analysis: changes in social isolation between the reconstruction housing and prefabricated housing groups

The two groups' LSNS-6 scores across the three data collection points $(4,5$ and 6 years after the GEJE) are shown in table 3 . At the baseline (4years post-GEJE), mean LSNS-6 scores did not differ significantly between the reconstruction housing and prefabricated housing groups (table 3). However, the GEE analysis showed that, over the subsequent 2 years, LSNS-6 scores worsened in the reconstruction housing group but slightly improved in the prefabricated housing group (table 3 ).

The rate of social isolation (LSNS-6 scores $<12 / 30$ ) across the three data collection points are shown in 
Table 3 Association between moving to public reconstruction housing and the Lubben Social Network Scale after the Great East Japan Earthquake

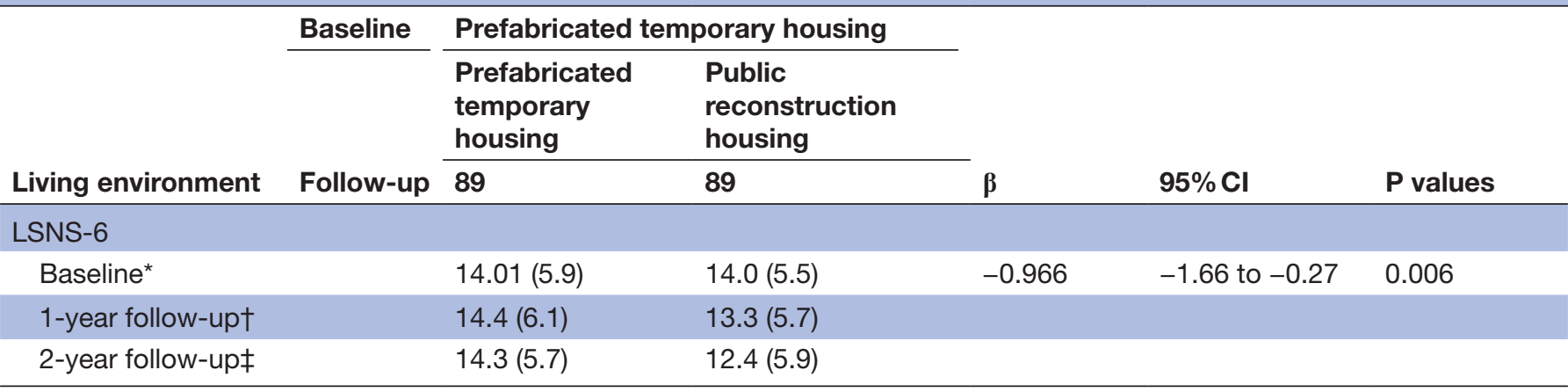

Data presented are mean scores (SD).

*Baseline: 4 years after the GEJE.

†1year follow-up: 5 years after the GEJE.

\$2year follow-up: 6 years after the GEJE.

GEJE, Great East Japan Earthquake; LSNS-6, Lubben Social Network Scale-6.

table 4. At the baseline, the rate of social isolation did not differ significantly between the public housing and prefabricated housing groups (table 4). However, the GEE analysis showed, over the subsequent 2 years, social isolation of the reconstruction housing group worsened whereas it improved in the prefabricated housing group (table 4).

In order to check robustness of the results, non-matched data analysis was conducted in the same manner. There were no significant differences found between the results of matched and non-matched data (online supplementary tables S1 and S2). The Cronbach's alpha coefficient for LSNS-6 ranged from 0.71 to 0.74 , and that for K6 ranged from 0.88 to 0.89 during the 2 -year study period.

\section{DISCUSSION}

In the present study, we examined the changes in social isolation between survivors who moved to public reconstruction housing during the 5th year after the GEJE and those who continued to live in temporary prefabricated housing. LSNS-6 scores deteriorated more among the former than the latter group, and the social isolation rate (LSNS-6 score <12) also increased more in the former group.

Sone et al previously reported that $24.9 \%$ and $26.0 \%$ of survivors were socially isolated at 1 and 3 years, respectively, after the GEJE. They also found a longitudinal association between social isolation and psychological distress. ${ }^{24} \mathrm{Com}-$ pared with their study, our data show a higher prevalence of social isolation at 4 years after the GEJE (34.3\%). One likely cause of this difference is the participants' living environment: our study focused on survivors who had lived in prefabricated temporary housing for at least 3 years; however, the previous study analysed the living environment data of all survivors, without any limitations. ${ }^{24}$ Our study's participants would have been forced to live in prefabricated temporary housing of similar areas for longer periods than participants of the previous study; therefore, the rate of social isolation at 4 years after the GEJE was higher than that of the previous study.

Table 4 Relation between moving to public reconstruction housing and the proportion of social isolation after the Great East Japan Earthquake

\begin{tabular}{|c|c|c|c|c|c|c|}
\hline \multirow[b]{3}{*}{ Living environment } & \multirow{3}{*}{$\begin{array}{l}\text { Baseline } \\
\text { Follow-up }\end{array}$} & \multicolumn{2}{|c|}{ Prefabricated temporary housing } & \multirow[b]{3}{*}{ OR } & \multirow[b]{3}{*}{$95 \% \mathrm{Cl}$} & \multirow[b]{3}{*}{$\mathbf{P}$ values } \\
\hline & & $\begin{array}{l}\text { Prefabricated } \\
\text { temporary } \\
\text { housing }\end{array}$ & $\begin{array}{l}\text { Public } \\
\text { reconstruction } \\
\text { housing }\end{array}$ & & & \\
\hline & & 89 & 89 & & & \\
\hline \multicolumn{7}{|l|}{ Social isolation } \\
\hline 2-year follow-up $\ddagger$ & & $24.7 \%$ & $43.8 \%$ & & & \\
\hline
\end{tabular}

*Baseline, 4 years after the GEJE.

†1year follow-up: 5 years after the GEJE.

†2year follow-up: 6 years after the GEJE.

GEJE, Great East Japan Earthquake. 
There are several possible explanations for the apparent association between moving to public reconstruction housing and increased social isolation. First, the survivors participating in this study had continued to live in temporary housing for more than 3 years due to the high risk of future tsunamis affecting coastal areas. A one-level prefabricated temporary house consists of five to 10 units, with one or two rooms in each unit. Such houses are likely smaller than the survivors' former residences, ${ }^{14}$ which can give them greater chances of seeing each other, resulting in the nurturing of interpersonal relationships. For those survivors subsequently relocated to public reconstruction housing, relationships built after the GEJE were destroyed, requiring them to again build new personal relationships. This could cause social isolation to increase. Second, residential forms differ substantially between public reconstruction housing and prefabricated temporary housing. Prefabricated temporary housing, which is designed for the practical purpose of fast erection, takes the form of a relatively small shelter, which could be conducive to the formation of relationships among survivors. ${ }^{14}$ By contrast, public reconstruction housing, which is intended to be permanent, takes the form of an apartment or a detached house. While inherently a more secure and stable form of housing, survivors occupying these properties may find it more difficult to build relationships within their neighbourhood. Third, the aims of public reconstruction housing and temporary housing differ. Since the main purposes of the former include promoting self-reliance among survivors, social support and social events held by volunteer groups and/or local governments might be weakened among survivors living in public reconstruction housing. Some strategies might be useful to eliminate social isolation, such as collective relocation and early moving plan. However, there would be several issues such as land acquisition, location condition, project funds and culture adaptation during the planning process.

Several studies have demonstrated that the strength of social networks can aid both short-term and long-term disaster recovery. ${ }^{26-28}$ Koyama et al concluded that the method of moving to temporary housing is an important predictor of access to social support. ${ }^{13}$ Our study suggested that moving to public reconstruction housing could put people at risk of having less social support in an ordinary manner after the GEJE. The approach for survivors who have been moved to public reconstruction housing should be more intense and thoroughly focused on improving disaster recovery to reduce suicide and dying alone, which were highlighted after the Hanshin Awaji Earthquake. ${ }^{18}$

This study has several strengths. First, it is the first to examine the association between moving to public reconstruction housing and social isolation among survivors of a natural disaster. Second, this study used a longitudinal design, requiring protracted efforts from the researchers and survivors to undertake surveys in the aftermath of the GEJE. Conversely, our study has several limitations. First, in absolute terms, our sample size of 393 was relatively small. Second, as a proportion of the 937 participants who lived in prefabricated temporary housing at 4 years after the GEJE, the analysed population of 393 (41.9\%) was relatively small, so our findings could be influenced by the healthy participant effect. Third, the participants had all lived in prefabricated temporary housing for at least 4 years. Since they had lived in the similar area, this study might overestimate their social ties existing in the GEJE-affected area. The survivors have been recruited by local governments to live in public reconstruction housing and decided to move to public reconstruction housing. There were some prioritisations (eg, aged households, families with children and with disabilities) to move to public reconstruction housing. Furthermore, low-income, vulnerable and older populations are often excluded from permanent housing programmes and choose to stay in temporary housing, ${ }^{29}$ which could lead to overestimation. However, the proportions of participants with social isolation (LSNS-6 $<12$ ) between the analysed and excluded participants did not differ substantially (34.3\% vs $32.1 \%)$.

\section{CONCLUSION}

Survivors who moved from prefabricated temporary housing to public reconstruction housing during the 5 th year after the GEJE suffered greater social isolation compared with those who continued to live in prefabricated temporary housing. Although public reconstruction housing is important for providing permanent and safe housing to survivors of natural disasters, it is also necessary to consider the reconstruction of social and interpersonal ties. Continuous social care should be provided to survivors relocated to public reconstruction housing.

\section{Author affiliations}

${ }^{1}$ Department of Orthopaedic Surgery, Iwate Prefectural Central Hospital, Morioka, Japan

${ }^{2}$ Department of Orthopaedic Surgery, Tohoku University Graduate School of Medicine, Sendai, Japan

${ }^{3}$ Division of Epidemiology, Department of Health Informatics and Public Health, Tohoku University School of Public Health, Graduate School of Medicine, Sendai, Japan

${ }^{4}$ Graduate School of Medicine, Tohoku University School of Public Health, Sendai, Japan

Acknowledgements We would like to thank Yoshiko Nakata, Mami Takahashi and Fukuko Kano for their technical assistance.

Contributors All the authors have made a substantial contribution to the manuscript and have approved this submission. TS participated in the design of the study and statistical analysis of the data, and wrote the manuscript. YH is the corresponding author of this study. YH participated in the design of the study and helped to draft and edit the manuscript. YS, YT and FT helped to analyse the data and draft the manuscript. YY and El helped to draft the manuscript. IT conceived the study, collected the data and helped to analyse the data and draft and edit the manuscript.

Funding This work was supported by Health Sciences Research Grants (H24, 25-Kenki-Shintei-002 [Fukkou]) from the Ministry of Health, Labour and Welfare of Japan.

Competing interests None declared.

Patient consent for publication Obtained. 
Ethics approval The study protocol was reviewed and approved by the Ethics Committee of Tohoku University Graduate School of Medicine.

Provenance and peer review Not commissioned; externally peer reviewed. Data sharing statement № additional data available.

Open access This is an open access article distributed in accordance with the Creative Commons Attribution Non Commercial (CC BY-NC 4.0) license, which permits others to distribute, remix, adapt, build upon this work non-commercially, and license their derivative works on different terms, provided the original work is properly cited, appropriate credit is given, any changes made indicated, and the use is non-commercial. See: http://creativecommons.org/licenses/by-nc/4.0/.

\section{REFERENCES}

1. Colantonio A, KasI SV, Ostfeld AM, et al. Psychosocial predictors of stroke outcomes in an elderly population. J Gerontol 1993;48:S261-8.

2. Orth-Gomér K, Rosengren A, Wilhelmsen L. Lack of social support and incidence of coronary heart disease in middle-aged Swedish men. Psychosom Med 1993;55:37-43.

3. Thurston RC, Kubzansky LD. Women, loneliness, and incident coronary heart disease. Psychosom Med 2009;71:836-42.

4. Cacioppo JT, Hawkley LC, Thisted RA. Perceived social isolation makes me sad: 5-year cross-lagged analyses of loneliness and depressive symptomatology in the Chicago Health, Aging, and Social Relations Study. Psychol Aging 2010;25:453-63.

5. Chou KL, Liang K, Sareen J. The association between social isolation and DSM-IV mood, anxiety, and substance use disorders: wave 2 of the National Epidemiologic Survey on Alcohol and Related Conditions. J Clin Psychiatry 2011;72:1468-76.

6. Teo AR, Choi H, Valenstein M. Social relationships and depression: ten-year follow-up from a nationally representative study. PLoS One 2013;8:e62396.

7. Blazer DG. Social support and mortality in an elderly community population. Am J Epidemiol 1982;115:684-94.

8. Steptoe A, Shankar A, Demakakos P, et al. Social isolation, loneliness, and all-cause mortality in older men and women. Proc Natl Acad Sci U S A 2013;110:5797-801.

9. Awata S, Seki T, Koizumi Y, et al. Factors associated with suicidal ideation in an elderly urban Japanese population: a community-based, cross-sectional study. Psychiatry Clin Neurosci 2005;59:327-36.

10. Zhao Y. Social networks and reduction of risk in disasters: an example of the Wenchuan Earthquake. Economic Stress, Human Capital, and Families in Asia: Springer, 2013:171-82.

11. Daniel PA, Michelle AM. Social capital and community resilience. Am Behav Sci 2014;59:254-69.

12. Ishigaki A, Higashi H, Sakamoto T, et al. The Great East-Japan Earthquake and devastating tsunami: an update and lessons from the past Great Earthquakes in Japan since 1923. Tohoku J Exp Med 2013;229:287-99.
13. Koyama S, Aida J, Kawachi I, et al. Social support improves mental health among the victims relocated to temporary housing following the Great East Japan Earthquake and Tsunami. Tohoku J Exp Med 2014;234:241-7.

14. Tanji F, Tomata Y, Sekiguchi T, et al. Period of residence in prefabricated temporary housing and psychological distress after the Great East Japan Earthquake: a longitudinal study. BMJ Open 2018;8:e018211.

15. Leelawat N, Suppasri A, Imamura F. Disaster recovery and reconstruction following the 2011 Great East Japan Earthquake and Tsunami: a business process management perspective. International Journal of Disaster Risk Science 2015;6:310-4.

16. Maly E, Shiozaki Y. Towards a policy that supports people-centered housing recovery-learning from housing reconstruction after the Hanshin-Awaji Earthquake in Kobe, Japan. International Journal of Disaster Risk Science 2012;3:56-65.

17. Reconstruction. Recovery and Reconstruction from the Great East Japan Earthquake: Reconstruction Agency. http://www. reconstruction.go.jp/english/topics/Progress_to_date/index.html (accessed 31 Jul 2018).

18. Kako M, Arbon P, Mitani S. Disaster health after the 2011 great East Japan earthquake. Prehosp Disaster Med 2014;29:54-9.

19. Gokon H, Koshimura S. Mapping of building damage of the 2011 Tohoku earthquake tsunami in Miyagi Prefecture. Coastal Engineering Journal 2012;54:1250006-1-12.

20. Hagiwara $Y$, Yabe $Y$, Sugawara $Y$, et al. Influence of living environments and working status on low back pain for survivors of the Great East Japan Earthquake. J Orthop Sci 2016;21:138-42.

21. Lubben J, Blozik E, Gillmann G, et al. Performance of an abbreviated version of the Lubben Social Network Scale among three European community-dwelling older adult populations. Gerontologist 2006;46:503-13.

22. Kurimoto A, Awata S, Ohkubo T, et al. [Reliability and validity of the Japanese version of the abbreviated Lubben Social Network Scale]. Nihon Ronen Igakkai Zasshi 2011;48:149-57.

23. Sekiguchi T, Hagiwara $Y$, Sugawara $Y$, et al. Influence of subjective economic hardship on new onset of neck pain (so-called: katakori) in the chronic phase of the Great East Japan Earthquake: a prospective cohort study. J Orthop Sci 2018;23:758-64.

24. Sone T, Nakaya N, Sugawara Y, et al. Longitudinal association between time-varying social isolation and psychological distress after the Great East Japan Earthquake. Soc Sci Med 2016;152:96-101.

25. D'Agostino RB. Propensity score methods for bias reduction in the comparison of a treatment to a non-randomized control group. Stat Med 1998;17:2265-81.

26. Aldrich DP, Meyer MA. Social capital and community resilience. Am Behav Sci 2015;59:254-69.

27. Nakagawa Y, Shaw R. Social capital: a missing link to disaster recovery. International Journal of Mass Emergencies and Disasters 2004:22:5-34.

28. Aldrich DP. The power of people: social capital's role in recovery from the 1995 Kobe earthquake. Nat Hazards 2011;56:595-611.

29. Ritchie LA, Tierney K. Temporary Housing Planning and Early Implementation in the 12 January 2010 Haiti Earthquake. Earthquake Spectra 2011;27(S1):S487-507. 